Lexis Vol. XLII (2) 2018: 369-404

\title{
Testimonio y ficción en la narrativa argentina
}

\author{
Victoria García \\ CONICET/ Universidad de Buenos Aires
}

\section{RESUMEN}

La relación entre testimonio y ficción representó, para los escritores latinoamericanos que promovieron el género testimonial en los años 60-70, una opción dilemática, entre términos claramente delimitados y mutuamente excluyentes. Sin embargo, reconsiderado hoy, el vínculo entre testimonio y ficción reviste una complejidad mayor, susceptible de ser abordada por la teoría literaria. En esta línea, nuestro trabajo estudia las relaciones entre testimonio y ficción que se despliegan en una serie de narrativas argentinas de posdictadura. Sostenemos que la articulación entre testimonio y ficción en dichas narrativas no se explica como un fenómeno meramente retórico, sino que responde a las características complejas de la experiencia social del terrorismo de Estado, que se representa en los textos considerados. A partir de un corpus amplio que abarca desde Recuerdo de la muerte de Miguel Bonasso (1984) hasta Tucho de Rafael Bielsa (2014), analizaremos algunos fundamentos histórico-sociales de la integración de testimonio y ficción en la narrativa argentina posdictatorial.

Palabras clave: testimonio, ficción, narrativa, posdictadura

\section{AbSTRACT}

The relation between testimony and fiction represented, for Latin American writers who defended testimonial literature in the 60-70s, a dilemmatic option, between clearly defined and mutually exclusive terms. 
However, reconsidered today, the link between testimony and fiction shows to be more complex, thus it can be addressed by literary theory. In such sense, this paper studies the relations between testimony and fiction displayed within a series of Argentine post-dictatorship texts. We argue that the articulation of testimony and fiction in such narratives cannot be merely explained as a rhetorical phenomenon. On the contrary, it derives from the complex characteristics of the social experience of State terrorism, which is represented in these texts. Based on a wide corpus which covers from Souvenir of the death by Miguel Bonasso (1984) to Tucho by Rafael Bielsa (2014), we analyze some socio-historical basis of the integration of testimony and fiction in Argentine post-dictatorship narrative.

Keywords: testimony, fiction, narrative, post-dictatorship

1. Testimonio y ficción: historia y teoría de una relación compleja

Los escritores latinoamericanos que, desde el final de la década de 1960, practicaron y promovieron el testimonio como una forma válida de hacer literatura, y se involucraron en la institucionalización del género que tuvo lugar en los círculos culturales cubanos, vieron en esa modalidad literaria "nueva” una alternativa estética y hasta una opción antagónica a la narrativa ficcional — sobre todo a la novela-, que había protagonizado el boom latinoamericano. En su conocido ensayo "La novela testimonio: socio-literatura”, de 1969, Miguel Barnet sostuvo: "La llamada ficción cada vez va perdiendo más consistencia” (101) y, un año más tarde, Rodolfo Walsh afirmó en la entrevista que mantuvo con Ricardo Piglia que "es probable que la ficción esté llegando a su esplendoroso final” (Piglia 1973: 18). Para ese momento, la narración de hechos reales constituía también un eje central del posicionamiento de Truman Capote en el campo estadounidense. Capote argüía que la non-fiction novel podía ser "tan interesante como la ficción” (Plimpton 1966): ambos géneros resultaban, para él, equiparables en potencial estético y en valor literario. En tanto, para los escritores latinoamericanos como Barnet y Walsh, la relación entre testimonio y ficción se presentó más bien como una disyuntiva. Priorizaron la literatura testimonial, 
reivindicándola por sobre y hasta en detrimento de la ficción, porque había una urgencia política a la que consideraban imperativo responder y, según diagnosticaban, esa respuesta la ofrecía el testimonio como herramienta estético-política, y no la narrativa ficcional.

La relación entre testimonio y ficción, que a los escritores politizados de los años 60-70 se les apareció como dilemática, plantea hasta hoy problemas cruciales de teoría literaria. En primer lugar, permite pensar la sociología del campo literario latinoamericano, en cuyo seno el debate sobre si hacer testimonio y/o novela, al que nos hemos referido, integró una disputa más amplia por el valor literario y hasta por la definición de la literatura —el nomos del campo, según Bourdieu (1995: 98-99)—, en un contexto en el que el compromiso político de los escritores tendió a instalarse como criterio de legitimación artística y cultural (cf. Quintero Herencia 2002: 371; Gilman 2003: 339 y ss.; Morejón Arnaiz 2006; Peris Blanes 2013; Forné 2014 y 2015; García 2012, 2013 y 2014a). La inclusión de la categoría Testimonio en el Premio Literario Casa de las Américas, en 1970, institucionalizó la alternativa testimonial dentro del espacio de los posibles del campo (Bourdieu 1995: 196). Ello propició, a la vez, la expansión del género en los años siguientes, así como dio legitimidad retroactiva a obras escritas antes de que el testimonio existiese como denominación genérica aceptada por los literatos -incluidas Operación masacre de Walsh y Biografía de un cimarrón de Barnet- ${ }^{1}$

\footnotetext{
1 Notemos que, en el contexto de la institucionalización del testimonio en Casa de las Américas, su concepción como modalidad narrativa opuesta a la ficción fue uno de los ejes sobre los cuales se forjó la legitimidad del género: “¿Se puede escribir un cuento, una novela, sobre los tupamaros y la lucha en el Uruguay?”, se preguntaba el autor de la reseña sobre La guerrilla tupamara de María Esther Gilio, que obtuvo el premio en Testimonio en 1970: "Sí, evidentemente. [...] Pero es en el testimonio donde se recogen los elementos que se encuentran en la sociedad, prontos para entrar en linotipo y ser divulgados masivamente" (Andrade 1971: 172-173). En la misma línea, Forné destaca que el jurado de 1972 definía el testimonio como "Una obra fiel a la realidad que enfoca y que descarta la ficción" (2015: 255).
} 
En segundo lugar, la relación entre testimonio y ficción permite introducir una serie de interrogantes importantes sobre los límites de la literatura, esto es, sobre su especificidad como práctica artística, dentro del conjunto amplio y heterogéneo de las prácticas verbales. No se trata solo de la cuestión sociológica de los límites que el campo literario define para sí, sino de un problema estético que, desde un punto de vista histórico, precede a la autonomización del campo literario como tal. ${ }^{2}$ En esta línea, Gérard Genette proporciona en Ficción y dicción algunas orientaciones conceptuales. Para el autor, la narrativa ficcional es constitutivamente literaria, pues en virtud de sus propiedades discursivas "entrar en la ficción es salir de la esfera ordinaria de ejercicio del lenguaje" (Genette 1993: 9-10). La narrativa testimonial, en cambio, integra un conjunto más esquivo de textos, cuyo estatuto literario surgiría solo en determinadas condiciones, debido a cualidades estéticas derivadas, a la vez, de ciertas características formales (Genette 1993: 22). Ahora bien, si se acepta esa literariedad condicional del testimonio, queda aún abierto el interrogante de cuáles son y cómo se establecen los rasgos formales que confieren a algunos textos testimoniales, y no a otros, un carácter literario (García 2015).

En tercer lugar, y en relación con lo anterior, el vínculo entre testimonio y ficción presupone y, al mismo tiempo, introduce la discusión sobre las fronteras entre el discurso narrativo factual y ficcional (cf. Ryan 1997; Schaeffer 2010; Caïra 2010; Lavocat 2016; García 2017). Se suele asumir que esa frontera existe, pues se la adopta como criterio - a menudo intuitivo y por ende implícito-

\footnotetext{
2 Seguimos aquí a Schaeffer (2006), quien señala que el interrogante por la especificidad de la literatura como arte verbal se encuentra presente en las reflexiones sobre los géneros literarios ya desde la Poética de Aristóteles. Según el autor, la persistencia histórica de la cuestión de la especificidad de la literatura se debe a que, a diferencia de lo que ocurre en otras artes como la música o la pintura, que son prácticas intrínsecamente artísticas, "la literatura o la poesía constituyen ámbitos regionales en el seno de un ámbito semiótico unificado más vasto, que es el de las prácticas verbales, ya que estas no son todas artísticas: el problema de la delimitación extensional y definicional del ámbito de la literatura (o de la poesía) puede parecer, pues, crucial” (Schaeffer 2006: 5-6).
} 
para circunscribir los objetos de la crítica literaria. ${ }^{3}$ Sin embargo, no hay consenso en los círculos académicos sobre los fundamentos teóricos de la oposición factual/ficcional. Jean-Marie Schaeffer (2010) apunta, en este sentido, tres perspectivas básicas: una semántica, que postula que la narrativa factual es referencial mientras que la narrativa ficcional no tiene referente en el mundo real; una sintáctica, según la cual narrativa factual y ficcional se diferencian por sus características lógico-lingüísticas, y una pragmática, que afirma que la narrativa factual ostenta pretensiones de veracidad referencial mientras que la narrativa ficcional no las tiene, pues instala un pacto comunicativo de fingimiento lúdico, en cuyo marco el carácter verdadero o falso de las declaraciones que componen el texto resulta irrelevante. Schaeffer argumenta en favor de una definición pragmática de la ficción (2002 y 2010). Sin embargo, admite a la vez que no es posible prescindir del todo de los criterios semánticos y sintácticos: por un lado, las entidades y los hechos inventados son por lo común la materia de la ficción — de allí que difícilmente pueda admitirse como ficcional un relato enteramente conformado por enunciados referenciales-; por otro, los textos ficcionales y factuales suelen diferir desde un punto de vista sintáctico —en particular, los procedimientos de focalización interna, característicos de la ficción, son inusuales en los textos factuales- (Schaeffer 2010). ${ }^{4}$

3 Los juicios intuitivos de ficcionalidad y factualidad no solo orientan las operaciones de la crítica literaria. Más aún, son centrales en la experiencia ordinaria de los discursos: como señala Schaeffer (2010), en las interacciones de la vida cotidiana "confundir un relato ficcional con uno factual (o viceversa) puede tener consecuencias dramáticas”. De allí que uno de los objetivos de la teoría de la ficción sea, en términos de Ryan, "explicitar los criterios intuitivos sobre los cuales se apoyan los juicios de ficcionalidad” (2009: 64). En la misma línea, véase la crítica de la autora a las perspectivas "panficcionalistas" que, con un criterio contraintuitivo, desestiman la importancia teórica de la oposición factual/ ficcional (Ryan 1997: 165).

4 La asociación entre la ficcionalidad de un discurso narrativo y el hecho de que incluya procedimientos de focalización interna se debe a que, en el mundo real y en los discursos factuales que lo representan, el sujeto solo tiene acceso a su propia interioridad (Schaeffer 2002: 249; Cära 2010: 94). De allí que la penetración de un enunciador narrativo en los pensamientos de terceras personas sea considerada por ciertos enfoques como característica y hasta definitoria del discurso ficcional (véase Hamburger [1957] 1995: 49 y ss.; Cohn 2000: 23-25). 
Lo que parece claro, dentro del conjunto de problemas que plantea la relación entre testimonio y ficción, es que no conviene reducirla a una oposición tajante, de términos claramente delimitados y mutuamente excluyentes, como tendieron a hacerlo los escritores latinoamericanos que defendieron fervientemente el testimonio en la Latinoamérica de los años 60-70. El mismo Walsh, que imaginaba su obra literaria como escindida entre una serie testimonial, directamente vinculada con la realidad agitada de su época, y una serie ficcional en la que el compromiso político era irrelevante o secundario, en rigor articuló testimonio y novela en su producción narrativa. Operación masacre es la obra memorable que es no solo porque aborda hechos reales importantes en la historia argentina y latinoamericana, sino porque lo hace en una forma literaria específica: incorporando modalidades narrativas características de la ficción y, en particular, del género policial que Walsh cultivó desde los comienzos de su carrera de escritor. Francisco Urondo, quien como Walsh vio limitaciones en la narrativa ficcional tal como se había concebido en el boom, para dar cuenta de la realidad política movilizada de su etapa, ${ }^{5}$ buscó superar esas limitaciones con un texto inequívocamente testimonial como La patria fusilada - transcripción de entrevistas a sobrevivientes de la masacre de Trelew, de 1973 - pero también con una novela como Los pasos previos (1974), que combinaba una trama ficcional sobre el campo cultural politizado de los 60, con la incorporación de textos periodísticos y políticos como materiales documentales. Hasta Julio Cortázar, que no participó de la defensa del testimonio que llevaron adelante Walsh y Urondo, intentó en Libro de Manuel (1973) una “convergencia de actividades [...] disímiles” (1973: 7): la integración de experimentación formal y contenido político, o de ficción y trabajo documental. ${ }^{6}$

\footnotetext{
5 En el artículo "Escritura y acción”, de 1971, sostiene: "la novela -la argentina, al menos- pareciera pasar por un momento de serias dificultades como género literario [...]. La narrativa no alcanza a ponerse a la altura de las circunstancias” (Urondo 2013: 398).

${ }_{6}$ Hemos propuesto en otro lugar un análisis comparativo de las articulaciones narrativas entre testimonio y ficción en obras de Walsh, Urondo y Cortázar, producidas al calor de la consolidación del testimonio como género literario en América Latina (García 2015).
} 


\section{Testimonio y ficción en la narrativa argentina de posdictadura}

En la posdictadura, el género testimonial cobra en la Argentina una vitalidad similar a la que había alcanzado durante su institucionalización en el campo latinoamericano, en los primeros años 70. En efecto, a partir de la recuperación de la democracia en 1983, el testimonio pasa a desempeñar un papel central en los procesos de memoria sobre el terrorismo de Estado (Calveiro 2006; Jelin [2002] 2012: 109 y ss.) —con los avances y retrocesos jurídicos, políticos y culturales que dichos procesos atravesaron desde la transición democrática (cf. Dalmaroni 2004; Pittaluga 2007; Gamerro 2015; García 2016)-.

Al tiempo que el testimonio recobra importancia en la literatura argentina, también resurgen sus vínculos con la ficción. Se ha sostenido, en esta línea, que las narrativas más recientes de posdictadura -en particular, las producidas por hijos e hijas de la generación militante de los años 70- incorporan un componente ficcional en la representación del terrorismo de Estado que estaba ausente de los textos "estrictamente testimoniales" de los primeros años de la democracia (Gamerro 2015: 510; Logie 2015: 76; Nofal 2015: 837). Sin embargo, ya en la literatura testimonial de la década de 1980 es posible rastrear inflexiones ficcionales, diferentes de las presentes en las narrativas de la generación de los hijos e hijas, pero no por ello menos significativas para el análisis.

Así lo veremos en las narrativas de posdictadura que analizaremos en los apartados que siguen. Se trata de una serie de textos que, de distintas maneras, representan el vínculo entre testimonio y ficción en su materialidad narrativa. Por un lado, incluyen un componente testimonial manifiesto: declaran o insinúan frente a los lectores que son relatos de hechos reales y exponen que han surgido de la experiencia de los autores o de testimonios recogidos por ellos. Por otro lado, estas obras incorporan formas narrativas de la ficción, en los distintos niveles del discurso que, según hemos señalado, intervienen en su definición: recrean o inventan hechos 
—nivel semántico—, adoptan procedimientos narrativos característicamente asociados a la ficción —nivel sintáctico-, y/o incluyen indicaciones metatextuales que explicitan o sugieren la recreación ficcional involucrada en el relato de hechos reales - nivel pragmático-.

Las articulaciones que estos textos producen entre testimonio y ficción dan lugar a genericidades diversas y complejas. En algunos casos, se trata de narrativa de no ficción -Recuerdo de la muerte de Miguel Bonasso (1984), La Voluntad de Eduardo Anguita y Martín Caparrós (1997-1998), Tucho de Rafael Bielsa (2014)—; en otros, de novelas basadas en hechos reales - El fin de la bistoria de Liliana Heker (1996)—; otros son testimonios ficcionalizados - La Escuelita de Alicia Partnoy (1986), Pasos bajo el agua de Alicia Kozameh (1987)—; otros, finalmente, son expresiones de la autoficción testimonial - Los compañeros de Rolo Diez (1987), La casa de los conejos de Laura Alcoba (2008), Pequeños combatientes de Raquel Robles (2013)—ㄱ.

La hipótesis central que orienta nuestro análisis sostiene que la integración de ficción y testimonio que se constata en los textos de la posdictadura argentina no se puede explicar como un fenómeno meramente retórico: no se trata solo de técnicas narrativas a las que recurren los autores para potenciar la eficacia y/o el valor estético de los relatos. Más bien, las diversas modalidades de la articulación de testimonio y ficción en la narrativa argentina de posdictadura se derivan de las características complejas de la experiencia social que estos textos se proponen representar: esto es, la violencia de Estado, que la literatura testimonial argentina y latinoamericana ha incorporado como uno de sus temas básicos. Intentaremos mostrar, así, algunos fundamentos histórico-sociales de la integración de testimonio y ficción en la narrativa argentina posdictatorial.

La complejidad genérica de estos textos, que combinan testimonio y ficción, ha sido señalada en estudios críticos previos: véase, entre otros, Vezzetti (2002), Longoni (2007), Nofal (2010), Castro (2011), Sillato (2013) y nuestro propio enfoque (García 2016). 
2.1. La ficción, en los límites de la verosimilitud histórica del testimonio

Diremos, en primer lugar, que en ocasiones la ficción se introduce en los textos testimoniales sobre el terrorismo de Estado como clave interpretativa de hechos que, por lo extremo de su violencia, resultan difíciles de asimilar a los parámetros de verosimilitud histórica aceptados en el contexto socio-cultural en que se producen estos textos. Dicho de otra manera: aquello que no se termina de admitir como posible dentro del mundo real —esto es, el mundo que se imagina y se asume como real—se interpreta como "ficción", en el sentido de experiencia históricamente inconcebible y, por eso, lindante con lo irreal.

Así lo vemos, incluso antes de la dictadura de 1976-1983, en Walsh: en Operación masacre, el escritor utilizaba términos ligados a la ficción para referirse a los fusilamientos de 1956 que narraba en el libro: "La historia me pareció cinematográfica, apta para todos los ejercicios de la incredulidad" (Walsh 1957: 11), escribe al referirse a su primera reacción frente al encuentro con uno de los sobrevivientes, Juan Carlos Livraga. Más adelante, reafirma sobre otro sobreviviente, Benavídez: "va a sucederle algo increíble, algo que, aún ubicado en esa noche de singulares aventuras y experiencias, parece arrancado de una novela" (Walsh 1957: 58). Cuando describe a Desiderio Fernández Suárez, jefe policial a quien señala como responsable de la represión en José León Suárez, lo caracteriza como una figura "casi novelesca" (Walsh 1957: 140). Al Walsh de 1957 los hechos que conoce cuando investiga le parecen extraordinarios, inverosímiles: en ese sentido dice que son novelescos. La magnitud de la represión de 1956, en efecto, no tenía precedentes en la historia argentina (Bayer, Borón y Gambina 2011: 92); por eso desestabilizaba los parámetros de verosimilitud histórica instalados en el momento en que Walsh escribe el texto (García 2015).

En la literatura testimonial de la posdictadura, el quiebre de los parámetros de verosimilitud histórica se observa en una dimensión amplificada, en la misma medida de la represión estatal. En esta línea, la experiencia de supervivencia en los centros clandestinos de 
detención, a la que se refieren muchos relatos testimoniales sobre la época, parece desestabilizar los límites de lo hasta entonces considerado como históricamente posible, y expandir esos límites hacia territorios desconocidos de la experiencia. ${ }^{8}$

Alicia Partnoy, en la "Introducción" de su libro La Escuelita —publicado en 1986, durante su exilio en Estados Unidos—, afirma: "Conocí solo una Escuelita; sin embargo, en nuestro continente hay muchas 'escuelas' cuyos maestros se especializan en enseñar a perder la memoria y la convicción ideológica a fuerza de tortura y humillaciones [...]. En esas Escuelitas, los límites entre la historia y las historias son tan tenues que ni yo misma los puedo detectar" ([1986] 2006: 18). "Story and history", dice la versión en inglés: así, con la ambigüedad semántica de los parónimos, Partnoy sintetiza las fronteras difusas entre la realidad de los centros clandestinos de detención y lo inimaginable de su extrema violencia. Para la autora, lo que resulta inconcebible no es solo la violencia sistemática ejercida como terrorismo de Estado, sino además el cinismo que sostiene ese ejercicio, realizado en nombre de una "pedagogía" supuestamente destinada a la "recuperación" ideológica de quienes, en realidad, son los oprimidos por el poder concentracionario.

En el centro de detención que funcionaba en la Escuela de Mecánica de la Armada, la experiencia límite del terrorismo de Estado y el proyecto de "recuperación" político-ideológica que impulsa se despliegan a gran escala. La (sobre)vida coexiste allí con la muerte, pero, inverosímilmente, esa coexistencia se impone como "normalidad" para los detenidos. 9 Así, en Recuerdo de la muerte de Miguel

\footnotetext{
8 Ana Longoni señala, en este mismo sentido, que: “El de los campos clandestinos de detención aparece como un espacio impreciso, un territorio desconocido, suspendido por fuera de las lógicas conocidas, el de las identidades reconocibles. Una realidad fuera del mundo, una ficción: así es vivida por los que los habitaron” (2007: 89). Cf. también Calveiro ([1998] 2008: 103).

9 Calveiro se refiere, en esta línea, a la "superposición de contrarios de una manera incomprensible" que signa las experiencias de supervivencia en los centros clandestinos de detención: "Por un lado, la existencia de lógicas incomprensibles, por otro, la ruptura y la esquizofrenia dentro de la lógica concentracionaria desquiciaban a los prisioneros e incrementaban la sensación de locura” ([1998] 2008: 80).
} 
Bonasso, la ESMA aparece caracterizada como un "reino de los espectros” (1984: 63). Su protagonista, Jaime Dri, define como “alucinación colectiva" la cena de Navidad de la que participa junto a otros prisioneros (Bonasso 1984: 93): el festejo navideño aparece como inverosímil, porque se ejecuta como si hubiese motivos para la celebración dentro de la ESMA.

De manera similar, en La Voluntad de Anguita y Caparrós, Graciela Daleo se resiste íntimamente a asumir la supuesta e impuesta normalidad del cautiverio, en oportunidad de una cena que ha sido obligada a compartir con su torturador y con la prisionera que la ha delatado: "Todo era tan incoherente, tan terrible, que Graciela no conseguía prever qué pasaría en el momento siguiente. El desconcierto era una forma espantosa del terror [...]. Graciela empezaba a adentrarse en esa dimensión inverosímil de la ESMA" (Anguita y Caparrós [1998] 2013: 270). El terrorismo de Estado opera, así, sobre los límites sociales entre lo que se asume como real y lo que se rechaza como inconcebible. El como si que se impone en los centros clandestinos de detención - un terror que pretende ser normalidad-, se denuncia como inverosímil, casi irreal, en los testimonios de quienes atravesaron aquella experiencia. De allí que múltiples referencias a la ficción se encuentren en los textos sobre la época.

\subsection{Las otras voces del testimonio}

La ficción no solo está presente en los relatos testimoniales sobre la dictadura por el rasgo inverosímil que muchos sobrevivientes atribuyen a la experiencia en los centros clandestinos de detención. También surge porque la supervivencia que constituye una condición de posibilidad del testimonio, está atravesada por la laguna que imprime en él la no-supervivencia (Agamben [1999] 2002: 33-34): la ausencia de los muertos por el terrorismo de Estado, cuya imposibilidad de hablar es constitutiva tanto del testimonio como de la dimensión ficcional que a veces se conjuga con él, para representar las voces que faltan en el discurso testimonial.

La incorporación al relato testimonial de las voces de quienes no pueden hablar en él no implica solo la representación narrativa 
de hechos reales vividos por el testigo y cuya factualidad, por lo tanto, aquel puede aseverar. Además, involucra un procedimiento de recreación y hasta de invención, pues incluso cuando se trata de sucesos que el testigo ha presenciado, difícilmente su relato podría reconstruir los sucesos con la fidelidad a los acontecimientos reales que sin embargo persigue - a veces, afanosamente-.${ }^{10}$

Algunos textos testimoniales defienden su factualidad irrebatible pese a las dificultades que conlleva reconstruir una historia atravesada por las ausencias de muchos que participaron en ella. Recuerdo de la muerte de Bonasso, que se postula como un relato "rigurosamente cierto" (1984: 404), incluye escenas cuyo estatuto factual no podría acreditar el autor, ni siquiera apelando al testimonio de Jaime Dri, que constituyó la fuente básica para la confección del texto. En efecto, no en todos los episodios que refiere el libro, vinculados con la prisión clandestina en la ESMA y en la Quinta de Funes, Dri ha estado alli para dar cuenta de que así ocurrieron. Hay situaciones solo conocidas por quienes las protagonizaron y que, en el momento en que se escribe el libro, están muertos (Foster 1995: 37; Strejilevich 2006: 91). Así ocurre con la intimidad de Raquel Negro y Tulio Valenzuela (vid. infra, $\$ 2.3$ ), cuya ficcionalización en los capítulos de la "Operación México" le valió a Bonasso críticas de sobrevivientes de la ESMA, enmarcadas en un cuestionamiento más general al punto de vista sobre la detención clandestina que el autor desplegaba en el texto. ${ }^{11}$

En La Escuelita, de Alicia Partnoy, el procedimiento de ficcionalización de la experiencia social que reconstruye el testimonio se despliega abiertamente. Si bien el texto no renuncia a la búsqueda

\footnotetext{
10 A este respecto, Caïra señala: “los muertos no pueden producir testimonios, y nadie está en condiciones de transmitírnoslos” (2010: 95) [nuestra traducción]. El autor incluye los relatos a cargo de personajes muertos dentro de lo que denomina "versiones incompatibles con la comunicación documental”, esto es, modalidades narrativas inconcebibles en el discurso factual y solo compatibles con el discurso ficcional (Caïra 2010: 92).

11 El mismo Bonasso ha relatado las discusiones que mantuvo con sobrevivientes de la ESMA en los momentos previos a la publicación de Recuerdo de la muerte. Véase la Edición definitiva del libro (Bonasso 1994: 464-465) y el racconto autobiográfico del escritor en Lo que no dije en Recuerdo de la muerte (Bonasso 2014).
} 
de la verdad - "Como sobreviviente, sentí que era mi deber ayudar y dar testimonio de lo ocurrido", dice la autora en la "Introducción" (Partnoy [1986] 2006: 13)—, la fragmentariedad del texto - compuesto por una serie de relatos breves- expone la fragmentariedad de la experiencia que refiere (Bermúdez-Gallegos 1990: 464). Algunos relatos del libro tienen como personajes y/o narradores a compañeros de cautiverio de la autora que han sido asesinados, según se denuncia en los Anexos documentales que cierran el texto. El monólogo interior, característico del discurso ficcional, le permite a Partnoy captar la resistencia íntima de los prisioneros frente a la represión a la que se ven sometidos. Así, el relato "La primera noche del Benja", cuyo protagonista es Gustavo Marcelo Yoti —asesinado en 1977—, resalta la identidad política del detenido que persiste en lo íntimo, frente al aniquilamiento tanto físico como simbólico que perseguía el dispositivo represivo: "No me olvidé que soy peronista, montonero, ni que bice todo lo que pude contra estos milicos..." (Partnoy [1986] 2006: 43).

Otra de las compañeras de cautiverio de Partnoy que ha sido asesinada, Graciela Romero, protagoniza en "Graciela alrededor de la mesa" un monólogo interior cuyo destinatario es su hijo por nacer: "El futuro va a ser tuyo. [...] No los perdones, hijo" (47), le dice imaginariamente. La proyección a futuro en los pensamientos de la detenida trasluce la situación de enunciación de la propia Partnoy: para el momento en que el libro se escribe, el hijo de Graciela aún está por ser, pues no ha sido recuperado luego de su nacimiento en cautiverio. El testimoniante que incorpora en su relato voces ajenas bajo la forma de la ficción se vuelve un enunciador polifónico de la experiencia que refiere. Esta, en efecto, no es individual, sino social. ${ }^{12}$ En esta línea, Alicia Kozameh, en Pasos bajo el agua (1987), inventa un personaje femenino, a quien denomina Sara, para contar su historia de detención clandestina en el "Pozo" de Rosario. Sara es y no es Kozameh, porque en ella se inscribe también la

12 En términos de Partnoy: "[my] first goal was to tell the stories of the others because [I] was the survivor, and [I] wanted to stress the collective" (citado en Betterman 2009: 44). 
experiencia de sus compañeras de cautiverio: "Lo sustancial de cada uno [de los relatos]”, afirma la autora en el prefacio, “es verdadero, sucedió, lo viví yo misma o lo vivieron otras compañeras y yo lo supe, aunque he reemplazado nombres o quizá detalles que para nada cambian, de hecho, la esencia de la cosa" (Kozameh 1987: 7). ${ }^{13}$ El libro, entonces, es un testimonio, pero no es solo eso. Kozameh cuenta su experiencia confiriéndole una "forma literaria” (1987: 7) y hasta una dimensión inventiva, que potencian la representatividad y el valor simbólico del texto.

\subsection{Ficción y distanciamiento}

En ocasiones, la ficción se integra al relato testimonial sobre el terrorismo de Estado, como una forma de distancia. El lenguaje de la ficción introduce, de hecho, una discrepancia respecto del lenguaje ordinario: una separación (nunca tajante) entre el mundo real al que pertenece el autor del testimonio - y los lectores-, y el mundo ficcional en el cual el autor-testigo se transfigura como narrador y/o personaje.

Para Alicia Kozameh, la distancia enunciativa que introduce la ficción es una condición de posibilidad del relato testimonial, especialmente cuando se trata de experiencias traumáticas: "Si tuviera que escribir un testimonio directo de los años dictatoriales, o de mi propia experiencia durante esa época, posiblemente lo haría aunque a costa de enfermarme severamente. La mediación de la ficción, lo que ya sabemos que es la distancia establecida por el juego/trabajo ficcional, por la idea de que los personajes no son uno mismo, me salva" (Boccanera 2000: 13). Aunque a primera vista parece que Kozameh opone testimonio y ficción, en realidad los concibe como complementarios: el discurso ficcional es, en sus palabras, el medio del testimonio, la forma que este toma para ser enunciado.

13 Llama la atención la similitud entre este pasaje del prefacio escrito por Kozameh y el final de "Emma Zunz", de Borges: "La historia era increíble, en efecto, pero se impuso a todos, porque sustancialmente era cierta. Verdadero era el tono de Emma Zunz, verdadero el pudor, verdadero el odio. Verdadero también era el ultraje que había padecido; sólo eran falsas las circunstancias, la hora y uno o dos nombres propios" ([1949] 1997: 76). 
Del mismo modo, la ficción para Kozameh no solo implica un "juego" - un como si lúdico, que define el funcionamiento de la ficción según las teorías pragmáticas (Schaeffer 2002)—, sino además un "trabajo": un compromiso serio con la labor literaria que conlleva la ficcionalización, pero también con el trabajo de memoria que despliegan los textos de Kozameh (Jelin [2002] 2012), debido a su dimensión testimonial.

Ahora bien: las distancias que surcan el testimonio cuando este se entremezcla con la ficción no son solo las vinculadas a la necesidad del sobreviviente-testigo de elaborar reflexivamente una experiencia que ha sido traumática. En Partnoy, además, hay una distancia asociada al extrañamiento: a la singularización que, en su libro, es a la vez condición de la supervivencia en la detención clandestina y condición de la escritura literaria. ${ }^{14}$ Los relatos de La Escuelita se centran en pequeños objetos y situaciones que, si en la vida fuera del centro de detención resultan habituales —automáticos-, en la prisión adquieren significación, pues permiten sobrellevar la rutina deshumanizadora de la experiencia concentracionaria. La cajita de fósforos que es la única posesión de la prisionera, su nariz que le permite ver por debajo de la venda, una conversación bajo la lluvia entre la protagonista y una compañera de cautiverio, son algunas de las pequeñas situaciones de la (sobre)vida que se narran en el libro, bajo la mirada extrañada y poética de Partnoy. ${ }^{15}$

La distancia que surge con la ficcionalización del testimonio sobre el terrorismo de Estado también se vincula con el exilio. En el

\footnotetext{
14 La relación entre ficción y singularización —en el sentido en que la definieron los formalistas rusos (Shklovski 1965) — reside en que el procedimiento mimético involucrado en la ficción opera por ejemplificación de aquello que representa, y no por generalización ( $c f$. Schaeffer 2002: 197-199). Dicho de otra manera, el discurso ficcional se refiere siempre a hechos y personajes singulares. En el mismo sentido, Hamburger señala que "la literatura no describe conceptos generales [...], sino [...] fenómenos individuales e irrepetibles” ([1957] 1995: 21).

15 Como lo señala Marta Bermúdez-Gallegos en un temprano estudio sobre La Escuelita: "El nombrar aquellos objetos (las chancletas, el pan, su diente guardado en una cajita de fósforos, la campera de Vasca la cual servirá como refugio a la narradora-testigo para soportar la desaparición de su amiga) que enlazan la vida de afuera con el cautiverio, parece ser el refugio ante la locura” (1990: 471-472).
} 
exilio se escribe, de hecho, buena parte de la literatura testimonial argentina, sobre todo la producida en los años 80. La Escuelita, de Partnoy, fue compuesto en los Estados Unidos. El libro conjuga la distancia espacial del exilio de su autora con la distancia temporal que separa a la historia — que transcurre en 1977, durante la dictadura - de la narración — que tiene lugar varios años después, en el contexto de la transición democrática-. Asimismo, un lapso temporal de dos décadas separa a la edición original, publicada en el exilio en 1986, de su edición en la Argentina, que se produce recién en 2006. No azarosamente, Partnoy titula la primera de las piezas narrativas de La Escuelita "Había una vez...", como introduciendo a los lectores en un mundo otro, un poco de cuento, en el sentido de distante de la realidad que presupone compartida con aquellos. En Estados Unidos, el libro circula como The Little School. Tales of disappearance and survival, título que remite a la tradición literaria de la ficción (a los cuentos de Edgar Allan Poe). En la edición argentina de 2006, en cambio, el libro pasará a ser La Escuelita. Relatos testimoniales. De este modo, la factualidad del testimonio se reafirma al volver este a su propio contexto, en el cual la realidad de los hechos que narra aparece como indubitable.

Un caso similar al libro de Partnoy es Los compañeros, de Rolo Diez. El texto se publicó inicialmente en 1987, en México, y recién en 2000 se editó en la Argentina. Los compañeros no solo surge de una situación de exilio - el autor, que militaba en el PRT-ERP, salió de la Argentina en 1977-, sino además la tematiza. Es desde la distancia asociada al exilio que el narrador y protagonista de la novela, llamado Roberto, reflexiona críticamente sobre las concepciones y las prácticas políticas que el mismo Diez ha sostenido como militante en tiempos de represión estatal. "Estamos tratando de aprovechar este período para tratar de entender por qué las cosas han ocurrido de ese modo, y nos proponemos cambiar y buscar formas correctas para continuar la lucha en nuestra patria" (Diez [1987] 2000: 187), le dice el protagonista a su compañera Mariana, durante una discusión que mantienen en Roma. Esa reflexión sobre la propia experiencia política, como el mismo personaje lo indica, 
se hace posible solo a la distancia: "esto solo puedo pensarlo hoy, a distancia de un año y mucho más” (Diez [1987] 2000: 197). ${ }^{16}$

El distanciamiento del sujeto de la enunciación respecto de la experiencia que es objeto de su relato testimonial involucra, a veces, una discrepancia lingüística. Partnoy tradujo su propio testimonio al inglés para publicarlo en los Estados Unidos, y tuvo que asumir el “costo estético" (Simón 2014: 34) que conllevaba despojar al texto en inglés de expresiones con profunda significación en el contexto argentino, pero incomprensibles para el público estadounidense. En cambio, Laura Alcoba, escritora de la generación de los hijos de militantes de los años 70, escribió La casa de los conejos (2008), Los pasajeros del Anna C. (2012) y El azul de las abejas (2013) en francés. Sus textos circulan en la Argentina mediados por la traducción de Leopoldo Brizuela (Duarte Dos Santos y Gasparini 2015). El problema de la traducción atraviesa la autoficción testimonial de Alcoba. El capítulo de su obra que mejor lo expresa es el que La casa de los conejos/ Manèges dedica a la palabra "embute", término perteneciente a la jerga militante de los años 70, para el cual la narradora-autora no encuentra traducción posible en francés: "Cuando pienso en esos meses que compartimos con Cacho y Diana, lo primero que viene a mi memoria es la palabra embute. Este término del idioma español, del habla argentina, tan familiar para todos nosotros durante aquel período, carece sin embargo de existencia lingüística reconocida" (2008: 47).

Alcoba ha sostenido que escribir sobre la experiencia argentina de la década de 1970 en lengua francesa constituye, per se, un acto de reelaboración ficcional: "Hablar de los Montoneros en La Plata, años 1975 o 1976, en francés ya es extraño, ya es un invento” (Wajszczuk 2012). Esa lengua extraña de la ficción se asocia, para la autora, a la necesidad de tomar distancia de una experiencia

\footnotetext{
16 Para Longoni, es desde el exilio que el personaje de Los compañeros puede interrogar las visiones "monolíticas" que ha sostenido durante su militancia: "a medida que el protagonista recoge testimonios de sobrevivientes ya en el exilio y ve resquebrajarse su punto de vista en la confrontación con los otros, [...su] tesitura se vuelve interrogativa, inquisidora antes que inquisitoria” (2007: 88).
} 
“que llevaba de manera tan dolorosa”, pero también se vincula con el contexto particular en el que escribe Alcoba, que imaginó un lector francés cuando concibió Manèges (Saban 2010: 247). Es en la interacción con ese lector que se instaura el pacto ficcional del texto. De hecho, ella misma señala que, en la Argentina, la recepción de La casa de los conejos estuvo más centrada en el contenido testimonial que en la forma ficcional del relato. ${ }^{17} \mathrm{La}$ ficción, en efecto, funciona como tal no en abstracto, sino para quienes la producen y la leen en cierta lengua y en determinado contexto. ${ }^{18}$

En Tucho. La «Operación México» o lo irrevocable de la pasión, de Rafael Bielsa (2014), el distanciamiento asociado a la novelización de hechos reales es, sin duda, uno vinculado al paso del tiempo. La novela se centra en la historia de Tulio Valenzuela, dirigente de la organización Montoneros que, durante su detención clandestina, simuló colaborar con el Ejército en una operación que tenía como objetivo capturar y asesinar a los miembros de la conducción de aquella organización, que se encontraban en México. El relato de Tucho contiene, sedimentadas en las voces del narrador y de los personajes, una serie de discusiones sobre la significación histórica de la experiencia argentina de los años 70. Si esas discusiones pueden introducirse en la novela, es porque se han acumulado como parte de los procesos de memoria desplegados en la Argentina desde la recuperación de la

17 La autora sintetiza en las siguientes palabras la ambigüedad entre ficción y testimonio constitutiva de La casa de los conejos, así como la incidencia del contexto en la recepción genérica del libro:

Puede haber una dimensión testimonial, pero para mí es importante que el libro se lea como una ficción. [...] Creo que si un libro está escrito o puede leerse como ficción, aunque la materia prima sea autobiográfica, permite al lector proyectarse y hacer esa historia suya también. [...] Pero la novela no se dirige solamente al colectivo de los argentinos; yo escribí el libro en francés pensando en un lectorado francés. [...] En Argentina la recepción fue particular porque entró en contacto con muchas historias personales dolorosas. Recibo constantemente cartas de lectores que me escriben no para hablarme del libro, sino de su relación con ese episodio de la historia argentina (Saban 2010: 248-249).

18 Acerca de los desfases que pueden producirse entre las intenciones ficcionales de los autores y las interpretaciones factuales de los lectores, véase Schaeffer (2002: 115 y ss.), Caïra (2010: 89-90) y Lavocat (2016). 
democracia en $1983,{ }^{19} \mathrm{y}$ también porque tales procesos cobran especial importancia política y cultural en el contexto en el que escribe Bielsa. De hecho, los capítulos finales de la novela tematizan los juicios por delitos de lesa humanidad cometidos en la Quinta de Funes, en los que el autor ha participado como testigo y que, como el mismo narrador lo indica, se produjeron "Más de treinta años después" de los hechos de la Operación México (Bielsa 2014: 187).

La diversidad de cuestiones éticas y políticas que Tucho aborda, la densidad conceptual que involucran, y la sutileza y la poeticidad con las que los personajes enuncian sus reflexiones caracterizan el modo en que Bielsa noveliza la historia protagonizada por Tulio Valenzuel $\mathrm{a}^{20}$. Pero no se trata simplemente de una recreación literaria que busca captar, apelando a la sintaxis de la novela, los hechos reales tal como ocurrieron. Los personajes que construye el texto son, en rigor, imposibles -inverosímiles - en el mundo real de los años 70 al que, sin embargo, pertenecen. La ficción sobre hechos reales surge, en Tucho, de hacerles pensar y decir a Tulio Valenzuela y Raquel Negro aquello que no habrían podido decir en su época y solo pueden decir en el contexto de escritura del libro, cuando los setenta son tema de profundos debates históricos y Tucho y María han podido convertirse en personajes de una novela.

Así, un anacronismo deliberado permea la recreación novelística de Bielsa. En ella, Tucho es capaz de anticipar su propia muerte - "Un cadáver postergado", se dice al comienzo del relato (Bielsa 2014:24)—, pero también de vislumbrar que, más allá de la dictadura, el impacto traumático de su muerte y la de otros miles de víctimas resultará duradero: para los padres — “ ¿Cómo harán nuestros

\footnotetext{
19 Bielsa señala en este sentido: "Los años modifican algunas perspectivas y, en mi caso particular, me han dado otra capacidad de comprensión y otro entendimiento. [...] Hoy uno entiende mucho más. Siempre la comprensión permite dar algunos pasos, la condena se termina ahí, uno condena y no entiende. Cuando uno trata de comprender, enriquece y matiza el pensamiento" (Méndez 2014) [subrayado nuestro].

20 El lenguaje poético de Tucho es, para el autor, una innovación que pretendió introducir en la tradición de la novela de no ficción: "El género no es una novedad en el abordaje. Es novela, pero la textura del lenguaje y la construcción tiene pretensiones poéticas” (Méndez 2014).
} 
padres para enterrarnos sin cuerpos que sepultar?" (181)_, para los hijos - “Un pueblo entero - no, no es bastante- la humanidad te servirá de padre", reflexiona sobre Quinqui, el hijo de Raquel Negro (176) — , para toda una generación por venir — “ ¿Y si esta dictadura puta termina por cortar la transmisión temporal y establece un vacío entre nuestra generación y la venidera?” (184) - y, más aun, para toda una nación de la que Tucho se reconoce como parte - "Es posible [...] que ganen esta guerra. Pero al costo de que la Patria pierda por mucho tiempo, por demasiados años, su conciencia moral” (Bielsa 2014: 150).

El Tucho de Bielsa es consciente de su inscripción subjetiva en un tiempo histórico que, eventualmente, habrá de ser otro y en cuyo después - la posdictadura- incluso la doctrina que él profesa - como militante de Montoneros-y las modalidades de su puesta en práctica - ligadas con el papel político que desempeñaron las cúpulas dirigentes de la organización - resultarán interrogadas: "Lo que hoy es doctrina antes fue otra cosa y será otra en el futuro. Y cuando haya otra doctrina [...] ¿será todavía una 'traición', para repetir las palabras del Tribunal Revolucionario?” (133-134). Tucho entiende, en suma, que él mismo en un futuro será pasado, o más bien memoria en la medida en que habrá quienes recuperen su testimonio y hasta lo re-presenten literariamente, como Bielsa en la novela: "Nuestros nombres van a ir pasando de mano en mano [...], para rendirnos homenaje [...]. Nunca se va a terminar nuestra historia, el pasado seguirá latiendo su desmayada vida de presente en el futuro" (178-179).

\subsection{Las “zonas grises” de los años 70. De la distancia al desentendimiento}

En ocasiones, la toma de distancia que conlleva la ficcionalización del testimonio linda con el desentendimiento o con la desresponsabilización enunciativa. En particular, algunas narrativas sobre hechos reales ocurridos en los años 70 han recurrido a la forma de la ficción para moderar las implicancias polémicas de la historia, especialmente cuando esta involucra cuestiones de difícil 
tratamiento o zonas grises del proceso político de los años 70, en las que "el oprimido se hace opresor" (Agamben [1999] 2002: 21).

A estas zonas de difícil tratamiento se refiere Miguel Bonasso en Recuerdo de la muerte, cuando afirma que dio al texto forma de novela porque dicho género "permite desenterrar ciertos arcanos que a veces se niegan a salir dentro de las pautas más racionales de la crónica histórica, el testimonio de denuncia o el documento político" (1984: 404) [nuestro subrayado]. Bonasso dice bajo la forma de la novela lo que no puede enunciar como testimonio directo. $\mathrm{Su}$ libro se refiere extensamente a la colaboración de los detenidos clandestinos durante la dictadura con sus represores y, en la misma línea, a los vínculos sexuales y amorosos entre captores y prisioneras. En relación con este último tema, el autor introduce un personaje que denomina Pelusa, cautiva que se involucra en una relación con uno de los represores de la ESMA. Bonasso ha sostenido, sobre dicho personaje, que "es el único nombre de fantasía que existe en Recuerdo de la muerte", que lo implementó para "Proteger una identidad" y que, por ese motivo, cualquier asociación entre el personaje y personas reales sería por él “desmentida enérgicamente” (2014: 28). Sin embargo, con esa postura el autor se desliga del compromiso que él mismo ha establecido al declarar que la historia contada en Recuerdo de la muerte es "rigurosamente cierta" (vid. supra, \$2.2.), declaración que queda desmentida con la incorporación al relato de un personaje que carece de correlato estricto con las personas reales que atravesaron la experiencia de la ESMA. ${ }^{21}$ En este sentido, la inclusión de Pelusa en el libro de Bonasso admite otras interpretaciones que las divulgadas por el propio autor. El personaje condensa una zona gris del terrorismo de Estado argentino cuyas implicaciones problemáticas Bonasso pretende eludir. Evita, de este modo,

21 La confusión que suscitó la inclusión de un personaje ficticio en un libro con pretensiones factuales es señalada por las sobrevivientes de la ESMA que conversan en Ese infierno, a propósito de un episodio televisivo protagonizado por el exrepresor Adolfo Scilingo: “Cuando Scilingo participó en el programa de televisión de Mariano Grondona nombró a Pelusa, que era un personaje imaginario, una licencia literaria del libro Recuerdo de la muerte. Hablaba de la situación de Pelusa como si hubiese ocurrido realmente” (Actis, Aldini, Gardella, Lewin y Tokar 2001: 203). 
la representación directa mediante el testimonio y apela a la forma de la novela, como si la autorreferencialidad de la literatura aplacase los efectos polémicos que el texto suscita al ser considerado desde una perspectiva política y ética. ${ }^{22}$

El caso del libro de Liliana Heker, El fin de la bistoria (1996), es similar al de Bonasso. Se trata de una novela cuyo componente testimonial la autora explicitó no en el mismo libro, sino en las intervenciones públicas que acompañaron su publicación. Heker sostuvo que se había propuesto "fundir los bordes entre ficción y realidad” (Russo 1996: 8), al componer una novela cuya protagonista no solo era una persona real, sino que además había mantenido amistad con ella. En el texto, Leonora —así se llama el personajees una militante de Montoneros que durante su cautiverio en la ESMA traiciona su identidad política y a sus compañeros, colaborando abiertamente con los represores e involucrándose en una relación amorosa con uno de ellos. La novela suscitó diversas críticas centradas, por un lado, en la perspectiva que Heker adoptaba para narrar la historia de los 70 - se focalizaba en un caso difícilmente representativo de la complejidad de aquella experiencia-, pero también dirigidas a la forma ficcional del texto. En este sentido, parecía que al novelar los hechos la autora podía apelar al carácter “puramente" literario de su apuesta narrativa, desentendiéndose así de las implicancias éticas y políticas problemáticas de la mirada que desplegaba sobre los años $70 .^{23}$

\footnotetext{
22 En esta línea, Longoni señala que textos como los de Bonasso: “a la hora de abordar los asuntos más escabrosos y dolorosos de vidas privadas [...] terminan apelando a la impunidad que les otorga su condición literaria” (2007: 199).

${ }_{23}$ Graciela Daleo, sobreviviente de la ESMA, sostuvo sobre el libro: "Si cuestiono la elección de 'Leonora' como protagonista me argumentarán el derecho de la autora a elegir sus personajes. Es ficción, dirán. ¿Ficción? Identidades disfrazadas en todo caso. La mayoría de los personajes es real, como lo es la historia central” (Daleo 1996: 6). Héctor Schmucler (1996), por su parte, cuestionó: “¿Qué extraña traición se teje entre el autor y su palabra cuando la tragedia — no es otro el tono que merece la agonía de las personas reales que padecieron el destino de Leonora- se resuelve en divertimento literario?" (1996: 11). Para una descripción detallada de la polémica sobre el libro de Heker, remitimos al trabajo de Demarchi (2003); para un análisis centrado en el tema de la traición como núcleo polémico del texto, véase el trabajo de Castro (2007).
} 


\subsection{Ficción y simulación}

La ficción, en ocasiones, se introduce en los textos testimoniales sobre los años 70 como una forma de representar las prácticas de simulación que atravesaron las experiencias militantes de aquella época, en particular las desarrolladas en la clandestinidad por las organizaciones político-militares como el PRT-ERP y Montoneros. El fingimiento sostenido que llevaron adelante los militantes clandestinos, para falsear sus identidades y encubrir el funcionamiento de las organizaciones a las que pertenecieron - frente a la amenaza permanente de la represión- (cf. Peller 2009), se recrea como fingimiento lúdico en narrativas sobre la dictadura que instalan un pacto de lectura propio de la ficción (Schaeffer 2002) sin dejar de contener, a la vez, un componente testimonial manifiesto. Dicho de otra manera: la ficción aparece, en ciertas narrativas de la postdictadura argentina, como una forma privilegiada de representar la "ficción” que sostuvieron los militantes clandestinos en sus vidas reales durante los años 70.

Los compañeros, de Rolo Diez, es una ejemplificación cabal del vínculo entre ficción y simulación en los textos sobre la experiencia argentina de la década de 1970. El fingimiento ligado a la militancia clandestina representa un modo de vida para el protagonista de la novela, Roberto, miembro del PRT-ERP: “Tremenda contradicción la de la gente que vive al mismo tiempo la vida del buen vecino y la conspiración más rigurosa. El tiempo que se pierde, la energía y los nervios que se gastan en realizar tal o cual movimiento, por si llega a ocurrir tal o cual cosa” (Diez [1987] 2000: 91), señala el narrador en uno de los pasajes del texto. Las alusiones a las dificultades que implicaba para los militantes clandestinos sostener cotidianamente una doble vida —un como si, similar a una ficción- son constantes en la novela. ${ }^{24}$

24 En muchos casos, el ejercicio constante de la simulación por parte del personaje se compara con el despliegue de una ficción teatral: "Manipuló los cigarrillos teatralmente, en esa representación tendida hacia la inercia de un solo espectador”, comenta el narrador en una escena en que el protagonista teme ser descubierto por las fuerzas represivas (Diez [1987] 2000: 64); “Fallaban los personajes de la obra”, señala acerca de un malentendido ocurrido en una reunión organizada en la clandestinidad (Diez [1987] 2000: 44). 
Pero no se trata solo de uno de sus núcleos temáticos centrales, sino también de un aspecto que permea su forma. En efecto, la doble identidad de Roberto se recrea en una estructura novelesca conformada a partir de distintos desdoblamientos. Por un lado, el personaje de Roberto es un doble ficticio del autor: así lo sugieren su nombre similar y ciertos indicios del paratexto, que informan que Diez militó en el PRT-ERP (Longoni 2007: 77-78). Por otro, el relato se desdobla sistemáticamente a través de la novela, en relato homodiegético —en el que Roberto narra su propio pasado- y heterodiegético — donde Roberto se ve como otro (como una tercera persona), compartiendo la militancia y la vida cotidiana con sus compañeros-. En el nivel de la historia que Roberto y el mismo Diez protagonizaron en los años 70, la simulación sostenida característica de la clandestinidad, se desarrolla con la seriedad que exigen el compromiso militante y el contexto represivo en que aquel se despliega. Pero en el nivel de la narración que construye el autor, el fingimiento adquiere matices lúdicos, ligados al pacto de lectura ficcional, y a la ironía con la que Diez recrea los complejos procesos identitarios vinculados a su militancia en la década de 1970.

En La Voluntad, de Anguita y Caparrós, la cuestión del fingimiento atraviesa los relatos sobre las experiencias de militancia en la clandestinidad. "Todo el tiempo tenía que andar inventando la historia de lo que estaba haciendo, por si lo paraba la policía”, dice el libro a propósito de Luis Venencio, militante de Montoneros ([1998] 2013: 28). El narrador oficia de traductor del "lenguaje cifrado" y los “códigos simulados” a los que recurrían los miembros de las organizaciones revolucionarias, frente a un lector extemporáneo a los años $70 \mathrm{y}$, sobre todo, a las jergas militantes de aquella época (Anguita y Caparrós [1998] 2013: 47). Es en los capítulos dedicados a Graciela Daleo donde el tema de la simulación adquiere una importancia central, pues Daleo recurrió al fingimiento que sostenía cotidianamente en su militancia en Montoneros, como estrategia de supervivencia al ser secuestrada y detenida en la ESMA. Daleo finge colaborar con los marinos y estar "recuperada" ideológicamente, pero en su interior se resiste 
a la destrucción de su identidad política que aquellos pretenden. ${ }^{25}$ Se trata de una situación compleja: “Todo el tiempo [Graciela] tenía la sensación de que estaba caminando sobre una Gillette: ¿yo soy la que soy o soy la que simulo ser? ¿No estaré pasando la raya, no me convertiré en aquella que estoy tratando de simular que soy para que ellos crean que estoy 'recuperada'?” (Anguita y Caparrós [1998] 2013: 270). La apelación al discurso indirecto libre en este pasaje de La Voluntad es significativa, porque se trata de un procedimiento de focalización interna, característicamente ligado a la narrativa ficcional (Hamburger [1957] 1995: 65-68; Schaeffer 2002: 249). En efecto, solo mediante la penetración en los pensamientos del "personaje" de Daleo el narrador —y los autores - consiguen captar el fingimiento que ella sostuvo como estrategia de íntima resistencia, frente al intento de "recuperación" desplegado por los marinos. El recurso a las formas narrativas de la novela define, más ampliamente, el modo en que La Voluntad reconstruye la historia política de los años 70. Si el libro consigue retratar las experiencias singulares de algunos sus protagonistas, es porque hace de los militantes una serie de "personajes" que cotidianamente hacen, dicen y piensan la política de la época ${ }^{26}$.

El tema del fingimiento cobra importancia, asimismo, en las más recientes narrativas de hijos e hijas de militantes de los años 70.

\footnotetext{
25 No solo Daleo recurrió al fingimiento como estrategia de supervivencia. Las mujeres sobrevivientes de la ESMA que escriben Ese infierno ubican en la simulación un aspecto central de su militancia y de su resistencia en la detención clandestina: "El tipo de militancia que teníamos, a medida que avanzaba la represión, nos llevó a una práctica de simulación ante los demás que luego nos sirvió para resistir dentro de la ESMA”, dice Munú Actis, y Liliana Gardella asiente: "Sí, tal vez por eso pudimos desarrollar la estrategia de fingir para defendernos de los marinos" (Actis et al. 2001: 37). Véase también Calveiro ([1998] 2008: 113-137).

26 Si bien La Voluntad se propone como "un intento de reconstrucción histórica" y sus autores señalan en la noticia preliminar que "Todo lo que se relata aquí es, hasta donde sabemos, cierto" (Anguita y Caparrós [1998] 2013: s/p), los vínculos del libro con la novela y con la non fiction son evidentes. El mismo Caparrós lo caracterizó en una entrevista como una "ficción política" que reconoce antecedentes literarios en la obra de Walsh y Urondo (Pérez 1998). Dentro de la crítica, la forma novelada del relato se señala tanto en una lectura en clave histórica como la de Vezzetti (2002: 220) como en los enfoques literarios de Nofal (2010) y Castro (2012).
} 
En Pequeños combatientes, de Raquel Robles (2013), es un tema central y, como ocurre en Los compañeros, permea la forma del relato. Los niños que protagonizan el libro de Robles, hijos de militantes montoneros secuestrados en la dictadura, simulan sistemáticamente imitando las prácticas políticas cotidianas de sus padres: "había que disimular, pasar por gente común, por víctimas del atropello. [...] Entonces dejé de hablar de táctica y estrategia [...], y me dediqué a disimular [...]. Volvimos a los entrenamientos, pero ahora en la clandestinidad" (Robles 2013: 12), anuncia la narradora al comienzo de la novela.

Aunque ella y su hermano pretenden tomarse la simulación en serio - como sus padres-, terminan involucrados en juegos de fingimiento cercanos a la invención ficcional y a la creación artística: el niño juega a formar un "Ejército de Resistencia” con sus compañeros del jardín de infantes (15); la niña, por su parte, asume de manera consciente la dimensión artística y estética de sus prácticas de simulación: "Simular en épocas de Resistencia era como ser actriz, y yo sabía que me salía bien” ( 64). Lo que importa destacar del libro de Robles es que el fingimiento, que es uno de sus temas centrales, se recrea en la forma de la novela. Así como la protagonista construye para sí una identidad fingida-ficticia que encubre frente a los otros su rol de "pequeña combatiente" - y de hija de desaparecidos - la misma autora produce, al escribir una autoficción, un ejercicio complejo de fingimiento. En la recreación ficcional de su propia vida, Robles finge lúdicamente ser otra - la narradora y protagonista de la novela $-{ }^{27}$ que, no obstante, es ella misma en cierto sentido - la niña que fue durante los años 70-. Robles exhibe, en los desdoblamientos identitarios de su personaje y de ella misma - autora que se re-presenta como protagonista de

\footnotetext{
27 Toda narración ficcional homodiegética — sea o no una autoficción- involucra un ejercicio de simulación y sustitución de identidad, según coinciden en señalar las perspectivas sintácticas y pragmáticas de la ficción (Genette 1993; Hamburger [1957] 1995, Schaeffer 2002). Ello se debe a que el narrador del relato ficticio en primera persona tiene una identidad propia - es un personaje-, a diferencia de lo que ocurre en la narrativa ficcional heterodiegética, donde el narrador es una voz que no se asocia a una identidad determinada.
} 
una novela-, la complejidad de su propio proceso de reconstrucción identitaria en tanto hija de desaparecidos. Como señala Gabriel Gatti, la "conciencia del carácter construido de cualquier identidad, una posición reflexiva respecto a lo ficticio del mecanismo que las sostiene" (2011: 178-179), son aspectos característicos de los procesos identitarios protagonizados por los hijos de desaparecidos en la década de 1970.

\section{Conclusiones}

Hemos explorado, a través del artículo, las relaciones entre testimonio y ficción que se despliegan en una serie de narrativas de la posdictadura argentina. Sostuvimos, como punto de partida del análisis, que la articulación narrativa de testimonio y ficción está presente en la literatura argentina sobre el terrorismo de Estado ya desde la década de 1980, y no solo en las producciones recientes de hijos e hijas de la generación militante de los años 70. En esta línea, consideramos algunas manifestaciones textuales de la integración de discurso testimonial y ficcional en las narrativas de posdictadura. Dichas manifestaciones abarcan desde el ya clásico modelo de la non fiction, en el que procedimientos típicos de la ficción se incorporan a narrativas con finalidad testimonial (como ocurre en La Voluntad), hasta genericidades más complejas, en las cuales el pacto de lectura es ambiguo, en ocasiones de manera deliberada. Así, la ambigüedad genérica no caracteriza únicamente a las autoficciones ( $c f$. Alberca 2007): ya en un texto como Recuerdo de la muerte de Miguel Bonasso, primera novela testimonial sobre la dictadura argentina —de 1984-, se integran la aspiración de veracidad y la inclusión de componentes ficcionales en la recreación literaria de sucesos reales.

Desde la no ficción y el relato testimonial ficcionalizado hasta la autoficción testimonial, la integración de testimonio y ficción es persistente en la narrativa argentina de posdictadura. Según hemos argumentado, las razones de dicha persistencia se hallan en las características complejas de la experiencia social que estos textos buscan representar. Hemos visto, en este sentido, el viso de 
inverosimilitud que presentan los hechos del terrorismo de Estado -que, debido a su extrema violencia, aparecen como increíbles o "novelescos" aun frente a quienes los experimentaron-. Señalamos, asimismo, la importancia que el discurso ficcional adquiere en la representación de las voces de quienes no sobrevivieron a la represión: los muertos, que no pueden hablar sino como personajes ficticios, y cuya ausencia atraviesa los relatos testimoniales sobre la dictadura militar. Por otro lado, observamos que la ficción introduce una distancia respecto de la esfera del lenguaje corriente, que traduce al relato testimonial distintas formas de la distancia ligadas a la experiencia social del terrorismo de Estado: la distancia del exilio, la del paso del tiempo - entre la dictadura y la democracia en que se escriben estos textos-, la distancia necesaria para poner en palabras acontecimientos traumáticos. El distanciamiento que involucra la ficcionalización de sucesos reales, además, da lugar a veces a una desresponsabilización enunciativa: allí, como hemos sugerido, la irreverencia lúdica de la ficción y sus pretensiones de autosuficiencia estética lindan peligrosamente con la elusión de la ética de la creación literaria. Hemos señalado que este riesgo se presenta, en especial, en narrativas que abordan zonas grises del terrorismo de Estado. Finalmente, vimos que la ficción se introduce en algunos textos de posdictadura para recrear el fingimiento que atravesó la vida cotidiana de los militantes clandestinos en los años 70, y al que algunos de ellos recurrieron como estrategia de supervivencia durante su detención en el período dictatorial.

Las narrativas de posdictadura que estudiamos, al combinar testimonio y ficción, se desplazan entre la búsqueda comprometida de la verdad - una construcción social que resulta imprescindible en los procesos de memoria sobre el terrorismo de Estado, para rebatir las tergiversaciones y los silenciamientos del discurso oficial-y las licencias liberadoras de la (re)creación ficcional. Estas, al dispensar a los autores de las exigencias de rigor histórico que pesan sobre el discurso factual, permiten ampliar las posibilidades narrativas y, con ello, introducir puntos de vista inusitados - a veces, disruptivos- en la retrospección reflexiva sobre la experiencia personal y 
social que emprenden los textos considerados. De hecho, es el foco en la experiencia de los sujetos lo que sustenta, en estas narrativas, la integración de testimonio y ficción: el testigo se transfigura allí en personaje, de modo tal que cada historia de (sobre)vida singular, lejos de perderse tras las generalizaciones de la Historia —a menudo impersonales-, aparece realzada por la mirada concreta, extrañada y particularizante propia de la ficción y de la creación literaria.

Finalmente, hay que decir que estas narrativas no dejan de hacer política (testimonio) mientras hacen literatura (ficción). Las oposiciones tajantes que orientaron la institucionalización del testimonio en los años 70, en virtud de la cual el género hoy representa en Argentina y América Latina una opción literaria válida, parecen encontrarse ya superadas.

\section{Referencias bibliográficas}

Actis, Munú, Cristina Aldini, Liliana Gardella, Miriam Lewin y Elisa TOKAR

2001 Ese infierno. Conversaciones de cinco mujeres sobrevivientes de la ESMA. Buenos Aires: Sudamericana.

Agamben, Giorgio

[1999] 2002 Lo que queda de Auschwitz. El archivo y el testigo. Homo sacer III. Trad., Antonio Gimeno Cuspinera. Valencia: Pre-textos.

Alberca, Manuel

2007 El pacto ambiguo. De la novela autobiográfica a la autoficción. Madrid: Biblioteca Nueva.

AlcobA, Laura

2008 La casa de los conejos. Trad., Leopoldo Brizuela. Buenos Aires: Edhasa.

ANDRADE, Joaquín

1971 "María Esther Gilio: la comunicación casi instantánea”. Casa de las Américas. 64, 172-176.

Anguita, Eduardo y Martín Caparrós

[1998] 2013 La Voluntad. Una historia de la militancia revolucionaria en la Argentina. Tomo 3: 1976-1978. Buenos Aires: Planeta. 
BARNeT, Miguel

1969 “La novela testimonio: socio-literatura”. Unión. 1, 99-122.

BAyer, Osvaldo, Atilio Borón y Julio Gambina

2011 El terrorismo de Estado en la Argentina. Apuntes sobre su historia y sus consecuencias. Buenos Aires: Instituto Espacio para la Memoria.

Bermúdez-Gallegos, Marta

1990 "The little school por Alicia Partnoy. El testimonio en la Argentina”. Revista Iberoamericana. LVI, 156, 463-476.

BETTERMAN, Brian

2009 Armar el rompecabezas. La memoria y la tortura en La Muerte y la doncella de Ariel Dorfman y La Escuelita de Alicia Partnoy. Jupiter, Florida: Florida Atlantic College.

Bielsa, Rafael

2014 Tucho. La "Operación México" o lo irrevocable de la pasión. Buenos Aires: Edhasa.

BOCCANERA, Jorge (ed.)

2000 Redes de la memoria. Escritoras exdetenidas. Testimonio $y$ ficción. Buenos Aires: Instituto movilizador de Fondos Cooperativos.

Bonasso, Miguel

1984 Recuerdo de la muerte. Buenos Aires: Bruguera.

1994 Recuerdo de la muerte. Edición definitiva. Buenos Aires: Planeta. 2014 Lo que no dije en Recuerdo de la muerte. Buenos Aires: Sudamericana.

BORGES, Jorge Luis

[1949] 1997 El Aleph. Madrid: Alianza.

Bourdieu, Pierre

1995 Las reglas del arte. Génesis y estructura del campo literario. Trad., Thomas Kauf. Barcelona: Anagrama.

CAÏra, Olivier

2010 Définir la fiction. Du roman au jeu d'échecs. París: EHESS.

Calveiro, Pilar

2006 “Testimonio y memoria en el relato histórico”. Acta Poética. 27, 65-86. 
[1998] 2008 Poder y desaparición. Los campos de concentración en Argentina. Buenos Aires: Colihue.

Castro, Virginia

2007 “La traición quebrada”. Prohistoria. XI, 11, 149-165.

2012 "La Voluntad. Una bistoria de la militancia revolucionaria en la Argentina, de Eduardo Anguita y Martín Caparrós: ¿un libro escrito para vender?”. En Actas del VIII Congreso Internacional Orbis Tertius de Teoría y Crítica Literaria [en línea]. Dirs., Teresa Basile y Enrique Foffani. La Plata: Facultad de Humanidades y Ciencias de la Educación. Consultado: 11 de enero de 2017. <www.memoria.fahce.unlp.edu.ar/trab_ eventos/ev.1638/ev.1638.pdf >.

CoHn, Dorrit

2000 The distinction of fiction. Baltimore: John Hopkins.

CORTÁzAR, Julio

1973 Libro de Manuel. Buenos Aires: Sudamericana.

DAleo, Graciela

1996 “Cuál es el fin de esta historia?”. Página/12, Suplemento Radar. 1, 4, 9.

Dalmaroni, Miguel

2004 La palabra justa: Literatura, crítica y memoria en la Argentina, 1960-2002. Mar del Plata: Melusina; Santiago de Chile: RIL.

Demarchi, Rogelio

2003 De la crítica de la ficción a la ficción de la crítica. Córdoba: Editorial de la Municipalidad de Córdoba.

DiEz, Rolo

[1987] 2000 Los compañeros. Buenos Aires: De la Campana.

Duarte dos Santos, Débora y Pablo Gasparini

2015 "En el embute del francés: sobre Manèges / La casa de los conejos de Laura Alcoba”. Alea. 17, 2, 277-290. https://doi. org/10.1590/1517-106x/172-277

ForNé, Anna

2014 "El género testimonial revisitado. El premio testimonio de Casa de las Américas (1970-2007”. El taco en la brea. 1, 216-232.

2015 "Una suma de negaciones: apuntes sobre el género testimonial y el Premio Casa de las Américas (1970-1976)”. 
Kamchatka. Revista de análisis cultural. 6, 251-267. https:// doi.org/10.7203/kam.6.7077

Foster, David

1995 Violence in Argentine literature. Cultural responses to tirany. Columbia: University of Missouri Press.

Gamerro, Carlos

2015 Facundo o Martín Fierro. Los libros que inventaron la Argentina. Buenos Aires: Sudamericana.

GARCíA, Victoria

2012 "Testimonio literario latinoamericano: una reconsideración histórica del género". Exlibris. 1, 371-389.

2013 "Diez problemas para el testimonialista latinoamericano. Los años 60-70 y los géneros de una literatura "propia" del continente". Castilla. Estudios de Literatura. 4, 368-405.

2014a "Testimonio literario latinoamericano: prefiguraciones históricas del género en el discurso revolucionario de los años 60”. Acta Poética. 35, 1, 63-92. https://doi.org/10.19130/iifl. ap.2014.1.433

2014b La obra testimonial de Rodolfo Walsh en el contexto argentino $y$ latinoamericano de los años 60-70. Tesis doctoral inédita. Buenos Aires: FFyL-UBA.

2015 "Testimonio y literatura. Algunas reflexiones y tres realizaciones en la narrativa argentina: Walsh, Urondo, Cortázar". Kamchatka. Revista de análisis cultural. 6, 11-38. https://doi. org/10.7203/kam.6.6837

2016 "Testimonio y ficción en la Argentina de la posdictadura: los relatos del sobreviviente-testigo". Revista chilena de literatura. 96, 73-100. https://doi.org/10.4067/s0718-22952016000200004

2017 “Teoría (y) política de la ficción”. Badebec. Estudios críticos. 13, 212-239.

GatTI, Gabriel

2011 Identidades desaparecidas. Peleas por el sentido en los mundos de la desaparición forzada. Buenos Aires: Prometeo.

GenETTE, Gérard

1993 Fiction and diction. Trad., Catherine Porter. Londres: Cornell University Press. 
GiLman, Claudia

2003 Entre la pluma y el fusil. Debates y dilemas del escritor revolucionario en América Latina. Buenos Aires: Siglo XXI.

Hamburger, Käte

[1957]1995 La lógica de la literatura. Trad., José Luis Arántegui. Madrid: Visor.

HeKer, Liliana

1996 El fin de la historia. Buenos Aires: Alfaguara.

JeLIN, Elizabeth

[2002] 2012 Los trabajos de la memoria. Lima: Instituto de Estudios Peruanos.

Kozamen, Alicia

1987 Pasos bajo el agua. Buenos Aires: Contrapunto.

LAVocat, Françoise

$2016 \quad$ Fait et fiction. Pour une frontière. París: Seuil.

LogIE, Ilse

2015 "Más allá del 'paradigma de la memoria'. La autoficción en la reciente producción posdictatorial argentina”. Pasavento. Revista de Estudios Hispánicos. 1, 75-89.

LONGONI, Ana

2007 Traiciones. La figura del traidor en los relatos acerca de los sobrevivientes de la represión. Buenos Aires: Norma.

Maingueneau, Dominique

2006 Discurso literario. Trad. Adail Sobral. San Pablo: Contexto.

MÉNDEZ, Matías

2014 "Rafael Bielsa: 'En los 70 detestábamos un cargo del Estado”. Infobae. 3 de agosto. Consultado: 11 de enero de 2017. <http:// www.infobae.com/2014/08/03/1585029-rafael-bielsa-en-los70-detestabamos-un-cargo-del-estado/>.

Morejón Arnaiz, Idalia

2006 "Testimonio de una casa". Encuentro de la Cultura Cubana. 40, 93-104.

Nofal, Rossana

2010 "Los personajes en la narrativa testimonial”. Telar. Revista del Instituto Interdisciplinario de Estudios Latinoamericanos. 7-8, 51-62. 
2015 "Configuraciones metafóricas en la narrativa argentina sobre memorias de dictadura". Kamchatka. Revista de análisis cultural. 6, 835-851.

PARTNOY, Alicia

[1986] 2006 La Escuelita. Relatos testimoniales. Bahía Blanca: La Bohemia.

Peller, Mariela

2009 "Identidades clandestinas. Política, moralidad y vida cotidiana en la literatura testimonial sobre la militancia guerrillera en Argentina”. Ponencia presentada en las XII Jornadas Interescuelas Departamentos de Historia. Bariloche, Argentina.

Pérez, Ana Laura

1998 "Fragmentos de un país todavía secreto". Clarín, Revista N. 22 de noviembre. Consultado: 24 de diciembre de 2016. <http://edant. clarin.com/suplementos/cultura/1998/11/22/e-01001d.htm>.

Peris Blanes, Jaume

2013 "'La palabra es de ustedes, me callo por pudor': antiintelectualismo y emergencia del testimonio en Cuba". Atenea. 508, 57-72. https://doi.org/10.4067/s0718-04622013000200005

Piglia, Ricardo

1973 "Hoy es imposible en la Argentina hacer literatura desvinculada de la política” (Reportaje de Ricardo Piglia a Rodolfo Walsh / marzo de 1970). En Un oscuro día de justicia. Rodolfo Walsh. México: Siglo XXI, 9-28.

Pittaluga, Roberto

2007 "Miradas sobre el pasado reciente argentino: las escrituras en torno a la militancia setentista (1983-2005)". En Historia reciente: perspectivas y desafíos para un campo en construcción. Comps., Marina Franco y Florencia Levin. Buenos Aires: Paidós, 125-152.

Plimpton, George

1966 "The Story Behind a Nonfiction Novel". The New York Times. 16 de enero. Consultado: 24 de noviembre. <http://www. nytimes.com/books/97/12/28/home/capote-interview.html>.

Quintero Herencia, Juan Carlos

2002 Fulguración del espacio. El imaginario espacial de Casa de las Américas (1960-1971). Rosario: Beatriz Viterbo. 
Robles, Raquel

2013 Pequeños combatientes. Buenos Aires: Alfaguara.

Russo, Miguel

1996 "No quise escribir la novela de la dictadura". Página/12, Suplemento Radar. 1, 4, 8-10.

RYAN, Marie-Laure

1997 "Postmodernism and the doctrine of panfictionality". Narrative. 2, 165-187.

2009 "Mondes fictionelles à l'âge de l'Internet". En Les arts visuels, le web et la fiction. Ed., Bernard Guelton. París: Publicaciones de la Sorbona, 66-68.

SABAN, Karen

2010 "Un carrusel de recuerdos: conversación con la escritora argentina Laura Alcoba”. Iberoamericana. LX, 39, 247-251.

SCHAEFFER, Jean-Marie

2002 ¿Por qué la ficción? Trad., José Luis Sánchez-Silva. Madrid: Lengua de trapo.

2006 ¿Qué es un género literario? Trads., Juan Bravo Castillo y Nicolás Campos Plaza. Madrid: Akal.

2010 "Fictional vs. factual narration". En The living handbook of narratology [en línea]. Eds. Peter Hühn et al Hamburgo: Hamburg University Press. Consultado: 10 de octubre de 2017. $<$ hup.sub.uni-hamburg.de/lhn/index.php?title=Fictional vs. Factual Narration\&oldid=2048>.

SCHMUCLER, Héctor

1996 “Los relatos de traición”. La voz del interior, suplemento Cultura. 24 de octubre. 11.

SHKLOVSKI, Víctor

1965 "El arte como artificio". Trad., Ana María Nethol. En Teoría de la literatura de los formalistas rusos. Comp. Tzvetan Todorov. México: Siglo XXI, 55-70.

Sillato, María del Carmen

2013 "El testimonio en el marco de la ficción narrativa: los relatos de Alicia Kozameh”. En Alicia Kozameh: Ética, estética, y las acrobacias de la palabra escrita. Ed., Erna Pfeiffer. Pittsburgh: Instituto Internacional de Literatura Iberoamericana, Universidad de Pittsburg, 45-57. 
SimÓN, Paula

2014 "Exilio y autotraducción en la narrativa testimonial concentracionaria argentina. El caso de The Little School. Tales of Disappearance E Survival in Argentina, de Alicia Partnoy”. Orbis Tertius. 19.20, 29-39.

STRejILEVICH, Nora

2006 El arte de no olvidar. Literatura testimonial en Chile, Argentina y Uruguay entre los 80 y los 90. Buenos Aires: Catálogos.

URONDO, Francisco

1974 Los pasos previos. Buenos Aires: Sudamericana.

2013 Obraperiodística completa. Buenos Aires: Adriana Hidalgo.

VeZzeTti, Hugo

2002 Pasado y presente. Guerra, dictadura y sociedad en la Argentina. Buenos Aires: Siglo XXI.

WALSH, Rodolfo

1957 Operación masacre. Un proceso que no ba sido clausurado. Buenos Aires: Sigla.

Wajszczuk, Ana

2012 "La ficción es liberadora”. La Nación. 13 de julio. Consultado: 13 de diciembre de 2016. <http://www.lanacion.com.ar/ 1489614-la-ficcion-es-liberadora>.

Recepción: 18/01/2017 Aceptación: 31/08/2017 